\title{
Limits to prediction: Europeanizing technology in an expert forum
}

\author{
Mads Dahl Gjefsen
}

Received: 3 July 2013 / Accepted: 13 September 2013 / Published online: 25 September 2013

(C) The Author(s) 2013. This article is published with open access at Springerlink.com

\begin{abstract}
EU expert institutions delivering policy advice about the promise of emerging technologies, help frame the issues that technologies might address. Their assumptions about European contexts for technology futures therefore warrant critical attention. Drawing on current theoretical work in science and technology studies, archival research and interviews with policy actors, this article examines the European Commission's recently established European Technology Platforms. It focuses in particular on the industry stakeholder group advising the Commission on carbon capture and storage, a technology with implications for several industry and policy sectors. The paper demonstrates how expert-produced technology scenarios build on assumptions (1) about the polities the technology is thought to serve, and (2) the political priorities that it might address. By showing how such assumptions affect on-going technology development efforts, the paper suggests ways for sociotechnical dynamics to be better appreciated within EU units for technology planning.
\end{abstract}

Keywords EU · Expert forums · Policy tools $\cdot$ Sociotechnical imaginaries $\cdot$ Strategic reasoning $\cdot$ Wicked problems

Driven by a need for strategic reasoning, a diverse array of new institutions designed to advise governments and policymakers on emerging technologies have emerged in recent years, drawing in part on concepts and methodologies from Futures Studies (FS). A long, if fragmented, tradition of examining the aims and means of prediction might enable scholars in FS and related fields to offer input to practitioners charged with delivering estimates and recommendations for

\section{D. Gjefsen ( $\triangle)$}

Centre for Technology, Innovation and Culture (TIK), TIK Centre, University of Oslo, P.O. Box 1108, Blindern, 0317 Oslo, Norway

e-mail: madsdg@cantab.net public policy — such as in the form of technology assessment methodologies involving diverse groups of stakeholders and experts [1]. Moreover, institutional developments that in certain ways operationalize FS approaches in a policy context, might offer interesting objects of study in their own right. Theoretical resources from science and technology studies (STS) are relevant in this context. STS scholars tend to study the societal and political dynamics around developments in science and technology with a so-called symmetrical approach, where the development and circulation of technologies and truth claims in society are explained sociologically, rather than as direct functions of their technological functions or epistemic validity $[2,3]$. This foundation has led STS scholars to investigate topics related to social organization and knowledge institutions, as well as the role of experts in controversies related to science and technology. These topics intersect with current FS conversations about stakeholder participation in foresight, and the impacts of prediction for societal institutions in the present [4-7]. Where units for strategic reasoning are established to deliver policy advice on emerging technologies addressing "wicked" environmental problems [8], STS-perspectives on expert predictions can yield useful insights into how public interests and political priorities are implicated in the process.

This article examines a new addition to the complex of expert bodies advising the European Commission (EC) on technological futures. Conceived by the EC in 2002 as a way to stimulate increased R\&D investments, European Technology Platforms (ETPs) are forums where experts and stakeholders formulate joint visions and recommendations about research directions and priorities for specific technologies [9]. Thirty-six ETPs currently cover emerging technologies in energy, environment and IT, as well as in areas of industrial production, food and medicine. ETP membersprimarily industry actors - finance most platform operations, while the EC maintains an observatory role and in some cases 
provide administrative support. Although varied in size, membership composition and activities, all platforms have formulated a common Vision Document for their respective technology and agreed on a Strategic Research Agenda (SRA), deliverables that are intended to inform the design of the European Framework Programmes for Research. The EC requires these documents to provide a "coherent and unified approach to tackle major economic, technological or societal challenges [10]." While the EC is not obliged to follow recommendations from ETPs, these units have in some cases become the "go-to" forums when expert advice on emerging technologies is needed for other areas of EU policymaking, and also sought to establish themselves as authoritative expert institutions in the public sphere. Such forms of less formalized activity, coupled with ETPs' status as expert forums charged with integrating strategic technical advice and prediction with perceived "economic, technological or societal challenges" warrants critical attention. To that end, this article investigates the activities of one ETP, exploring how it anticipates and addresses public concerns about its technological area and which pathways of political and societal development are implicated in the production of its technological visions.

Some FS scholars have pointed to the limitations on predictive expertise when it comes to the societal implications of developments in science and technology [11, 12], indicating that issues of stakeholder participation and representational legitimacy are particularly important in cases where prediction deals with contentious technologies - a core research area in STS. The following article therefore focuses on the activities of an ETP formed around a technology that has at times been the subject of heated public debate and protests. Carbon dioxide capture and storage (CCS), for which the Zero Emissions Platform (ZEP) ETP was established in 2005, is a suite of technologies designed to limit greenhouse gas emissions by capturing $\mathrm{CO} 2$ from large stationary emission sources and transporting it for permanent storage in geological formations deep underground. Its primary area of application is power plants running on fossil fuels, but it can also find uses in industrial production. CCS draws on technological processes that are generally described as proven, but not yet commercially viable, and tends to be included amongst the technologies that are needed to mitigate climate change [13, 14]. However, it has also been the source of public fears and controversies about the safety of $\mathrm{CO} 2$ storage [15], and divided environmental non-governmental organizations (ENGOs) on questions such as whether public investments in CCS divert funding from renewable energy technologies [16].

The article proceeds by outlining relevant literature and methods, before presenting ZEP's visions and recommendations for CCS. It goes on to discuss how ZEP might be considered an authority on CCS, as well as its approach to publics and their concerns. The institutional design of ETPs and the political priorities that ZEP's visions and activities have become entangled with are also discussed. The article concludes that predictions about technological development allows potentially contentious societal choices to be masked as technological ones, and that increased attention to the sociotechnical dynamics of technology-driven visions, drawing on insights from FS and STS, could add necessary transparency and legitimacy to the activities of expert forums, consistent with current EC guidelines.

\section{Literature and methods}

This article draws on a strand of literature that investigates the political dynamics of technology by examining the patterns of power and authority it facilitates, and by being attentive to the range of social practices and governance structures that emerge around it $[17,18]$. Rather than demarcating science and technology as separate from societal structures, the article attempts to understand how ZEP's visions and strategies for CCS assume particular paths of co-production [19], where technological development and social life develop dialectically. In this spirit ZEP's descriptions and depictions of CCS are treated here as expressions of sociotechnical imaginaries [20], founded not only on technical predictions but also on assumptions about social change and stability. This approach responds to recent calls in FS scholarship for heightened awareness of the political pathways and institutional factors that enable or constrain the efforts to realize futures that are envisioned as desirable [21], supplementing it by also addressing the constellations of power that such visions assume. The article is explorative, and adopts an STS-approach to "opening up" assumptions and implicit framings that underlie expert predictions and recommendations about the future [22]. Without seeking exhaustive answers, it aims to investigate the range of ways that ETPs help shape ideas about both the polities and policies that technologies might serve.

ZEP's activities are explored using a combination of qualitative case study methods [23]. Policy documents outlining the rationale behind ETPs, as well as ZEP's Vision Document and Strategic Research Agenda for CCS, are investigated by asking theory-driven questions about the range of political priorities the platform has become associated with. In order to examine the platform's less regulated activities outside of its formalized inputs to the EC, ZEP publications targeting the general public are also examined. The aim is to understand the design and rationale behind communication efforts in relation to ZEP's conceptions about European publics, rather than to measure its impact. To illuminate strategic choices underlying ZEP's CCS scenarios, minutes from the meetings of ZEP's constituent working groups-publicly available from zeroemissionsplatform.eu - are consulted. Eleven semistructured interviews with past and current ZEP personnel and EC civil servants were carried out in Brussels, Paris and 
through teleconferencing, ranging between 30 and $60 \mathrm{~min}$, with the aim of exploring questions that were not generally addressed in official publications. Interviewees were recruited through direct contact with individuals involved in the drafting of relevant official documents. Possible directions and approaches for future research are given in the conclusion.

\section{A vision and a strategy}

Six months after its official launch in December 2005 ZEP released its Vision Document for "Zero Emissions Fossil Fuel Power Plants [24]." The EC requires all ETPs to formulate such a document in order to unite platform members around a shared set of ambitions that can guide their efforts to recommend priorities and strategies for research and development in the European Union (EU) [10]. ZEP's members at the time included ENGOs and research units funded by member state governments, though the majority of members were from industry companies. ${ }^{1}$ Their vision portrayed CCS as a way to reconcile ambitious European commitments to climate change mitigation with increasing energy demands and the need to maintain global competitiveness for European industry. The need for CCS was demonstrated with reference to warnings from the Intergovernmental Panel on Climate Change (IPCC) about the consequences of inaction on climate change, and to predictions by the International Energy Agency (IEA) that world energy demand would increase massively between 2004 and 2030, with fossil fuels continuing to dominate the global power generation market. ZEP laid out a vision of zero emissions fossil fuels power plants by 2020 , to be achieved through EU and member state research support which would stimulate industry confidence and willingness to invest in CCS, and effective dissemination to "improve public understanding that the technologies are safe and reliable and that substantial benefits will be gained from their deployment [10]."

The platform subsequently released an SRA describing the technology development efforts that would realize ZEP's vision [25], as well as a Strategic Deployment Document (SDD), outlining possible political and regulatory measures to stimulate CCS [26]. These documents-later revisedrecommended the establishment of 10-12 large-scale CCS demonstration projects across "the length and breadth of

\footnotetext{
${ }^{1}$ At the time of writing, ZEP's webpage presents organizational membership as divided into Government (2), NGOs (3), Companies (24), and Academia \& Research (7). A similar estimate is given in minutes from the Advisory Council meeting of February 22, 2006, which states that out of 93 individuals representing ZEP's organizational members, $60 \%$ come from industry, $30 \%$ from the research community, and $10 \%$ from NGOs "and similar organizations."
}

Europe," which would both test technological processes and "demonstrate the safety of $\mathrm{CO} 2$ geological storage" in order to influence public perceptions. Indeed, public support was identified as a crucial factor for the future of CCS, and several research recommendations were explicitly presented as aiming to provide evidence to sway public opinion and persuade publics of the desirability of CCS, rather than to address technological knowledge gaps. Elaborate recommendations were made for how research on public perceptions of CCS could contribute to increasing levels of support for the technology. The 2020 timeline set down in ZEP's vision document was presented as an argument for immediate initiation of political and regulatory measures to support CCS-steps which ZEP claimed would increase industry willingness to take financial risk and invest in the technology. Concrete recommendations included incentivizing geological $\mathrm{CO} 2$ storage under the newly launched EU Emissions Trading System (ETS) - the world's largest cap and trade system and a cornerstone in the EU's climate change mitigation strategy - and the establishment a regulatory framework for $\mathrm{CO} 2$ storage across EU member states.

ZEP's vision was thus translated into a research strategy whose realization depended on synergies with political incentives, regulatory frameworks and public opinion. More than simply a prediction about a state of technological development and a plan for reaching it, ZEP's vision for CCS can be seen as a sociotechnical imaginary built on assumptions about the organization of political and economic structures - for example with regards to the timing and design of EU funding mechanisms - as well as about the form and purpose of regulation. These assumptions continue to influence the platform's own attempts to establish public support, as well as the EU's political pursuit of CCS as a pathway to energy security and environmental sustainability.

\section{Envisioning publics}

One starting point for understanding ZEP's role as an expert institution is its approach to public communication. From the time of its founding ZEP maintained a designated Public Communication Taskforce alongside its taskforces on Demonstration \& Implementation, Technology, and Policy $\&$ Regulation, whose efforts are coordinated with the platform's leadership in ZEP's Advisory Council. Early meetings in the communication taskforce were characterized by uncertainty about its assignment, as well as about who their target audiences were and how they should be approached. At the taskforce meeting on December 182006 initial formulations of its objective included "educate, get rid of ignorance," "advocate and push for CCS implementation in Member States" and "provide information but also sell CCS." The assumption within the taskforce appears to have been that its 
role was to provide ways to frame CCS efficiently and positively, and discussion summaries indicate a conscious effort to establish at least an appearance of dialogical engagement with autonomous publics, recommending the use of the term "“inform' rather than 'educate' (too arrogant)."

The taskforce does not do or initiate its own research on public engagement with CCS, as the SRA might suggest. Nor does it attempt to directly engage with publics, despite ZEP's emphasis on public attitudes to CCS as a critical concern. Instead the platform maintains a public presence at events, such as the annual Conference of the Parties to the UN's Framework Convention on Climate Change, and produces communication materials on CCS that are distributed online and to platform members and EU member state governments for use in various educational efforts. Communication strategies are formulated in response to the findings of a designated Eurobarometer on awareness and acceptance of CCS [27], commissioned by the EC, where surveys of public attitudes in $12 \mathrm{EU}$ member states found that CCS is relatively unknown, that it is not as well favored as renewable energy technologies, and that a number of misconceptions - such as the belief that $\mathrm{CO} 2$ can explode - might lead publics to be skeptical of the technology. ZEP's publications address these findings by seeking to build awareness and correct misunderstandings about the technology, with advocates attempting to further the technology by "[redefining] the social as barriers to be overcome and approach[ing] it as what they must do to make the technical successful [28]." Like with other ETPs [29], ZEP's self-expressed concerns about the importance of public attitudes to their technological area have become coupled with public engagement efforts aimed at establishing public acceptance, rather than on facilitating civic deliberation. Indeed, interviews indicated that the marketing of the organization itself was seen as a central objective of its communication activities, and that the production of a clear brand identity for ZEP, expressed through unified design elements and a new logo, were seen as important achievements.

The pamphlet The hard facts behind CCS [30], illustrates the geological processes by which $\mathrm{CO} 2$ becomes "trapped" in storage reservoirs, explaining that technological development is dependent on EU funding, legislation and accelerated permitting processes. EU regulation requiring safe and permanent storage of $\mathrm{CO} 2$ is referenced as a guarantee of predictability and success. Another pamphlet, $\mathrm{CO} 2$ Capture and Storage (CCS): Why It Is Essential to Combat Global Warming [31], states that while replacing fossil fuels with renewable energy is "the ultimate goal," CCS offers the sustainable use of fossil fuels, and is a necessary transitory step because renewable energy is currently unable to "sustain even a basic standard of living." The continued reliance on fossil fuels is presented as inevitable. Few attempts are made to distinguish between normative and technical aspects of CCS, and the technology is described as facilitating European energy demands to be met while boosting European economy and industry competitiveness. ZEP's pamphlets are described as presenting the joint recommendations of "European industry, environmentalists, scientists and geologists."

As educational tools, these pamphlets give insight into how ZEP envisions its publics and their concerns, as well as the specific aspects of CCS that such publics are thought able to form meaningful opinions about. The platform appears to operate with a deficit model view of an uninformed polity that will lend its support to CCS if only provided with enough accurate technical information [32]. As one interviewee stated, much time and energy was spent on ensuring that all facts and figures in ZEP's publications were as accurate as possible. However, there seemed to have been less critical attention given to the broader narratives of a European purpose for CCS. Rather than approaching publics as having diverse interests and concerns about CCS that need to be addressed through engagement, ZEP's publics seem to be cast as unable to formulate autonomous opinions about the relative desirability of CCS compared with other climate change mitigation technologies and strategies, and as passive targets for information.

ZEP's publications present a sociotechnical imaginary of CCS as a pathway to protecting and maintaining current European lifestyles and economic structures, while simultaneously strengthening unitary conceptions of "European economy" and "European industry" as defined against the outside world. Tensions and conflicting interests between industries and member states within the EU are not addressed. Sustaining industry and fossil fuel based power generation is presented as integral to upholding current standards of living. The inevitability of continued demand for fossil fuel based power generation is not problematized, and CCS is instead portrayed as a technology whose only risks and uncertainties are technical in kind and thus controllable by experts.

These unitary visions obscure tensions between ZEP's constituent members. Archival and interview research indicate how communication choices have been shaped by ZEP's institutional design and the EC's expectations for how ETPs should envision technological futures.

\section{Consensus by design}

While ZEP's communication activities seem to address a homogenous European public, its institutional design has strong influence over how its members come to formulate shared research recommendations. ZEP's role as an expert body consulting the EC implies epistemic authority, while the inclusion of ENGOs in the platform implies at least some degree of representational legitimacy. ZEP has the characteristics of a boundary organization capable of displaying different forms of authority depending on the context [33]. Neither the ENGOs nor the private companies involved in the 
platform hold unified positions on CCS. ENGO members, while generally supportive of CCS as a strategy for ecological modernization [34], pursue the sharing of technical expertise, intellectual property issues and regulatory questions in ways that at times conflict with the aims of the platform's commercial members. Industry, in turn, are clustered into three factions - equipment suppliers, utilities, and oil and gas - each with their own sets of interests in the future of CCS. ZEP's constituents cover a broad range of positions on what aspects of CCS should be incentivized and on which CCS-related research should be supported by the EU, establishing the ETP as a forum for strategic negotiation about the distribution of research funds and policy priorities. The platform's privileged position as research advisor depends on presenting joint recommendations to the EC, forcing platform members to negotiate and arrive at unified proposals for the future of the technology. In this, the ETP serves as an obligatory passage point that requires actors with an interest in CCS to participate and cooperate on shared recommendations in order to maintain the status as the official representative of CCS stakeholders vis-à-vis the EC [35]. Interviews indicated that this institutional design fostered negotiations within factions as well, as one ZEP representative stated:

Each [constituency] has a designated person that represents that group. And their role is to communicate on behalf of their constituency. So where there are issues of disagreement, there they are able to articulate that. But equally their role is to gain consensus within their constituency on various affairs. So if someone came back from the utilities and said "hey, we've got five utilities for, we've got ten against, and five in the middle, "it doesn't help anything. The point is, what can you agree on and then move forward as a platform.

In the time leading up to ZEP's establishment, the EC drew on this institutional characteristic in order to secure "neutrality" in ZEP's expert recommendations, and "credibility" in its public communication efforts. Civil servants explained in interviews that the $\mathrm{EC}$ had presented the participation of NGOs as a criterion for officially recognizing the platform. While this had not been required of previous ETPs, it was thought that NGOs would add necessary credibility to a platform consisting primarily of members from fossil fuels industries.

So we thought that it was a good position to get a kind of a neutral view [and that NGOs were likely to] push forward things like more research on monitoring or tighter regulation on monitoring and that sort of thing.

Minutes from the September 42007 communication taskforce meeting illustrate how ZEP foregrounds ENGO members in order to inspire public trust and add weight to the argument of the urgency of CCS.
ETP ZEP is not a credible body to communicate the message an NGO is more credible. In addition [...], the current key message - CCS as a key solution for combating climate change-is too complicated (less complicated message: 'enabling zero emission power plants'). As urgency of climate change and large scale deployment of CCS are important topics/ problems, involvement of the public at large is crucial. A simple message to inform and convey the public that CCS is necessary is therefore crucial (they don't need further explanation).

While intended by the EC as a "check" on the possible interest bias of industry members, the ENGOs involved in ZEP thus appear to also have provided strategic leverage to the platform's public communication efforts. ZEP's information pamphlets frequently refer to the platform's recommendations as the joint advice of European industry and environmental groups, projecting the image of an inclusive stakeholder forum operating around a shared technological vision. However, the institutional design of ETPs has established boundaries as well. While CCS-skeptical Greenpeace participated in the preparatory stages of ZEP's formation, it was reported at the communication taskforce meeting of December 18, 2006 that the organization had withdrawn from the platform "since it feels that the Commission is pushing too hard for CCS without listening to [ENGOs]." The World Wide Fund for Nature, WWF, followed suit shortly after. In 2008 Greenpeace International released a report explaining its opposition to CCS, citing not only the types of health and safety risks of CCS generally addressed in ZEP's current information material, but also skepticism towards broader societal implications of the technology [36]. Such implications include the potential of CCS to sustain the global dependence on fossil fuels, disincentivize renewable energy development, and dissuade political measures to change energy intensive consumption patterns. As Corry and Riesch have aptly shown, ENGOs who oppose CCS are not simply driven by a fear of technical risks and hazards, but also by more complex lines of opposition to the socio-economic arrangements that the technology is thought to facilitate or sustain [37]. In Dryzek's terms, the rationale of CCS-skeptical ENGOs reflect survivalist and green radicalism thinking, schools of environmentalist thought that run counter to those seeking convergences between environmental protection and economic growth [34]. While ZEPs communication of CCS focuses on performance aspects and risks that are manageable by experts through technology and regulation, the societal structural grounds for skepticism toward CCS expressed by Greenpeace and other CCS critics, are largely ignored. The broader implication appears to be that in the case of technologies associated with environmental policy, the ETP format carries a bias against ENGOs skeptical of constructing environmental governance around market mechanisms and technology optimism. 
In withdrawing, Greenpeace relinquished their formalized influence over EC research priorities offered by ETP participation. The requirement that ETP members reach and support joint recommendations to guide the pursuit of technological futures appears to underwrite two distinct processes of coproduction. It ensures the mutual constitution of technological advice and societal organization in the present, and it stimulates the production of scenarios where technologies serve desired economic and political structures in sociotechnical imaginaries for the future. In the process, definitions of who constitutes stakeholders of technological change are streamlined, and dissent effectively managed through self-exclusion.

\section{Envisioning a political technology}

ZEP's vision for CCS was not simply of the realization of an isolated technology, but also one of political possibility, where achieving "zero emission power plants by 2020 " would jointly address issues across policy sectors. CCS represented the potential for a unique technical fix to a particular constellation of political problems potentially reconciling EU energy needs with ambitious commitments to climate change mitigation.

This point was foregrounded in ZEP's presentations of its research recommendations, helping to establish the platform as offering input to a broader range of political processes than what had previously been customary for ETPs. One EC representative explained that while many ETPs only interacted with EC coordinators in the department, or DirectoratesGeneral (DG's, comparable with national ministries) for Research and Innovation, the multi-sectorial relevance of ZEP and CCS had led policy officials from numerous DGs to become attentive to the platform's activities and recommendations. Minutes from the policy and regulation taskforce meeting of April 19, 2007 show that the platform delivered joint platform positions to a range of EC bodies on issues such as the inclusion of CCS in the EU ETS carbon market to the Environment DG, and that it gave input on financial incentives to the DG for Transport and Energy and on state aid to the DG for Competition.

Interviewees in the $\mathrm{EC}$ gave diverging answers when asked directly if they thought ZEP influenced other areas of EU policy besides research. While some civil servants insisted that ZEP was purely a research advisor, others stated that in practice the platform opened lines of communication through which CCS stakeholders could give input to different areas of EU policymaking. Interviewees were clear, however, that representatives from the full range of EC departments working on issues of relevance to CCS would regularly attend ZEP meetings to give updates on current and future developments in their policy areas. While this paper cannot speak to the actual extent to which ZEP might have influenced the design of EU policy strategies, the platform's archives give some indication that
ZEP's formal tasks as research advisor allowed it to also operate as a hub through which informal communication between a broad range of European CCS stakeholders and EC officials could take place. As one interviewee put it, the platform has in effect become "a reference point for Europe."

While ZEP's vision of emissions free power plants were epistemically justified in relation to expert assessments by the IPCC and the IEA about the prospects and potential consequences of increasing atmospheric $\mathrm{CO} 2$ content, the mechanisms that the platform proposed as ways to realize this sociotechnical imaginary, cannot be divorced from choices about mechanisms of governance. They included recommendations about the design of fiscal incentives, the establishment of regulatory frameworks, the clarification of liability issues and division of responsibilities between industry and national governments, the development of risk management strategies, and, as discussed above, the importance of gaining public support [26].

Some of these mechanisms have become political realities during the course of ZEP's existence. Political support for CCS in EU federal level policy has been on the rise since around 2005, paralleling increased political attention to the technology in several of its member states, and developed alongside a number of EU efforts to meet climate change mitigation commitments [38]. In line with recommendations made in ZEP's SRA, regulatory standards in the form of a CCS directive, the inclusion of CCS in the EU's ETS carbon market, and the formalized goal of up to 12 large-scale CCS demonstration plants across the EU have all been formulated and pursued by the EC and the EU Council of Ministers in this period. Nilsson and colleagues have argued that there is a tendency for strategic planning units in public policy to ignore political and institutional pathways and barriers to desirable futures [21]. ZEP actually appears to be highly aware of the importance of such pathways in their research recommendations. But when it comes to public communication materials explaining the form and purpose of CCS, the institutional and socio-political implications of the technology - the broader economic and environmental governance contexts that would lend meaning to CCS - are rarely discussed. This contrast is striking in light of the EC's stated ambitions regarding expert advice, to which we now turn.

\section{Summary discussion}

The ETP format has taken shape alongside attempts by the EC to institutionalize mechanisms for civic representation in expert forums. Partly in response to criticisms about EU technocratic governance [39], the EC has sought to clarify its routines for the collection and use of expertise over the early 2000s [40, 41]. In line with the rationales given in the FS literature for inclusive approaches to technology assessment [12], new guidelines for the use of expert advice in strategic 
planning and foresight have called for variously defined "interested parties" to be consulted, with the explicit aim of adding legitimacy to issue definitions and problem framings [42]. These ambitions were applied to ETPs from their very inception, when the EC recognized that since "technology platforms address major economic and societal challenges, the societal dimension should be taken into account throughout their development [10]." However, ETPs have not simply been charged with predicting the future of new technologies, but also with proposing strategic measures by which technological development can be put to the service of European integration both by facilitating EU stability and growth, and by catering to and helping to create an envisioned European public. Platforms were instructed to establish "an ongoing communication process, with a view to raising public awareness and enhancing dialogue on the justification for concentration of efforts at a European level in the technological field concerned [10]."

With ZEP, these ambitions appear to have translated into an approach to public communication where ENGOs are foregrounded both as guarantors of the "neutrality" of technical advice, and as ensuring that "societal dimensions" are appropriately addressed. But ENGO inclusion does not necessarily contribute to broader aims of representational legitimacy or to the deeper rationales of the technology assessment approaches that appear to have inspired the EC's changing ambitions for the use of expertise. As we have seen, the requirement that ZEP must present unitary positions forces members to negotiate both between and within constituent factions in order to formulate joint recommendations. For certain ENGOs, the risk of becoming associated with positions that they fundamentally oppose outweighs the benefits of the opportunity to influence the platform from within. Both the notion that "neutrality" could be ensured by ENGO participation, and the repeated claims that platform views represent the joint position of European industry, government and ENGOs, ignore the fact that ENGOs skeptical or opposed to CCS saw no choice but to withdraw from the platform. CCS opposition and skepticism has been based in part on a rejection of the notion that an increased demand for energy generation from fossil fuels is inevitable - a basic premise for ZEP's sociotechnical imaginary of CCS as the necessary technological fix for interlinked policy problems in the areas of energy and climate change mitigation. It seems possible that precisely the absence of members critical about the broader sociotechnical implications of CCS has contributed to shaping ZEP's communication efforts, which assume a deficit model of publics where audiences are seen as passive benefactors of CCS, expected to support the technology when presented with expert assurances about technical safety.

ZEP consistently presents CCS as a way to reconcile the EU's ambitions for climate change mitigation with an expected rise in energy demand. As Claes and Frisvold have shown, CCS could completely alter the position of coal, turning it into "the most abundant, reliable and inexpensive energy source in Europe [43]." ZEP's vision of zero emissions fossil fuel power plants implies that coal can be both legitimate from an environmental perspective, and profitable within the context of the European carbon market. In this respect, ZEP's vision reformulates political problems and priorities by deferring to the prospects of interrelated change in technological systems and mechanisms of governance. Thus, the platform's scenarios justifying the pursuit of CCS can be seen not simply as discursive moves to reframe narratives on fossil fuels, or as transparent and accountable policy advice, but also as sociotechnical imaginaries implying promises about material, social and political organization [20]. ZEPs imaginary of a European CCS-future implicates a diverse range of infrastructural and market networks connecting fossil fuel extraction with political and societal organization, ultimately shaping what Michell refers to as "the forms of democratic politics that carbon energy [makes] possible [44]."

When understanding the role of ETPs in shaping political concerns, it might be useful to not simply look at how these forums present emerging technologies as ways to achieve sectorial goals, but also to consider their function as a new form of European space. ETPs were originally conceived as a way of contributing to the institutionalization of the European Research Area - an ongoing effort since 2000 - and assumptions about European unitary interests underlie much of their output and the duties formulated for them by the EC. In his foreword to ZEP's 2006 vision document, the then Commissioner for Science and Research Janez Potocnik stated that zero emission power generation could both stimulate and benefit from processes of European integration [24]. As described in this article, ZEP's publications tend to present European industry, economy, publics and political concerns as units defined against the outside world, free from internal tensions or inconsistencies. The institutional design of ETPs demands that platform members negotiate and arrive at joint positions that in turn can be presented as the common recommendations of public and private European stakeholders. These boundary organizations thus serve purposes beyond their technological areas, as the production of technological visions becomes entangled with the joint production of European publics and political strategies.

\section{Conclusion}

This article has drawn on FS and STS literature in order to explore how a new institutional unit for technological foresight and advice to the EC has (1) formulated particular ideas about public concerns and how to address them, and (2) produced a vision for a CCS-future with implications not only for the technology itself, but also for the organization of a wide range of social and political structures around it. In 
contrast with understandings of technology as defined by its technical functions - "The only reason to build a CCS plant is to avoid atmospheric emissions of $\mathrm{CO} 2[45]$ " - the construction of ZEP's recommendations implicates a diverse network of European actors, whose stakes in the technology are defined in relation to sociotechnical arrangements, rather than against isolated technical properties. This case thus illustrates how units of foresight can be seen as producing sociotechnical imaginaries with important co-productionist implications, which in ZEP's case consisted of authoritative and "policy-ready" expert advice produced alongside formulations of pan-European economic and political interests, and constructions of knowledgedeficient publics ready to be persuaded by experts. While the role of ENGOs have helped illustrate this in the case of CCS and ZEP, it is not unlikely that similar dynamics are at play in other ETPs dealing with technologies which, even if less overtly controversial, nevertheless implicate choices about governance mechanisms and societal arrangements. Processes of issue framing and stakeholder representation in ETPs therefore deserve further study.

Alongside the implications of ZEP's strategic reasoning for the future, the establishment and operation of this technology platform also attributes legitimacy to certain CCS stakeholders as EC-sanctioned experts in the present, excluding others in the process. As one might expect, ZEP has sought to influence domains beyond its narrowly defined obligations to the EC, and the platform has established informal lines of communication both within the EC complex and in the public domain to those ends. While it has been beyond the scope of this article to measure the relative success of these efforts, it has sought to identify them as areas in which more work is needed, if the EC's stated aims for transparency and representational legitimacy in the use of expert advice are to be achieved. The inclusion of NGO representatives is not necessarily sufficient, and additional aims, strategies and methodological approaches to technology assessment might be needed in order to pursue these ambitions within the ETP framework.

\footnotetext{
Acknowledgments I am grateful for valuable comments on this paper from my PhD advisors Göran Sundqvist and Sheila Jasanoff, as well as for helpful advice from two anonymous reviewers. I also wish to thank Brice Laurent and Elizabeth Barron for commenting on earlier drafts. This work was carried out during a Visiting Fellowship at the Program on Science, Technology \& Society at Harvard University's Kennedy School of Government. It has been supported by grants from the Research Council of Norway (project 209247/V11), the Ryoichi Sasakawa Young Leaders Fellowship Fund, Legatet "Patrick Geddes-samlingen", Ella og Robert Wenzins legat ved Universitetet i Oslo, Jansons legat, as well as the Norway-America Association's Ragnhild Marianne Løkens Education Fund and King Olav V Stipend.
}

Open Access This article is distributed under the terms of the Creative Commons Attribution License which permits any use, distribution, and reproduction in any medium, provided the original author(s) and the source are credited.

\section{References}

1. Parandian A, Rip A (2013) Scenarios to explore the futures of the emerging technology of organic and large area electronics. Eur J Futur Res. doi:10.1007/s40309-013-0009-2

2. Bloor D (1976) Knowledge and social imagery. Routledge, London

3. Pinch TJ, Bijker WE (1984) The social construction of facts and artefacts: or how the sociology of science and the sociology of technology might benefit each other. Soc Stud Sci. doi:10.1177/ 030631284014003004

4. Epstein S (1996) Impure science: AIDS, activism, and the politics of knowledge. University of California Press, Berkeley

5. Collins H, Evans R (2007) Rethinking expertise. University of Chicago Press, Chicago

6. Loveridge D, Saritas O (2009) Reducing the democratic deficit in institutional foresight programmes: a case for critical systems thinking in nanotechnology. Technol Forecast Soc Chang. doi:10.1016/j. techfore.2009.07.013

7. Slaughter R (1996) Critical futures study as an educational strategy. In: Slaughter R (ed) New thinking for a new millennium: the knowledge base of futures studies. Routledge, London, pp 137-154

8. Sardar Z (2010) The namesake: futures; futures studies; futurology; futuristic; foresight — what's in a name? Futures. doi:10.1016/j. futures.2009.11.001

9. EC (2003) EC COM (2003) 690 final/2 A European Initiative for Growth. European Commission. http://ec.europa.eu/ten/transport/doc/ 2003_11_11_prov_report growth_initiative_en.pdf. Accessed 13 June 2013

10. EC (2004) Technology Platforms: from Definition to Implementation of a Common Research Agenda. European Commission. ftp://ftp.cordis. europa.eu/pub/technology-platforms/docs/tp_report_defweb_en.pdf. Accessed 16 June 2013

11. Eerola A, Miles I (2011) Methods and tools contributing to FTA: a knowledge-based perspective. Futures. doi:10.1016/j.futures.2010. 11.005

12. Cagnin C, Loveridge D, Saritas O (2011) FTA and equity: new approaches to governance. Futures. doi:10.1016/j.futures.2010.11. 006

13. Pacala S, Socolow R (2004) Stabilization wedges: solving the climate problem for the next 50 years with current technologies. Science. doi: $10.1126 /$ science. 1100103

14. Stern N (2007) The economics of climate change: the Stern review. Cambridge University Press, Cambridge

15. Feenstra CFJ, Mikunda T, Brunsting S (2010) What happened in Barendrecht? Case study on the planned onshore carbon dioxide storage in Barendrecht, the Netherlands. ECN, GCCSI. www.csiro. au/files/files/pybx.pdf. Accessed 13 June 2013

16. Anderson J, Chiavari J (2009) Understanding and improving NGO position on CCS. Energy Procedia. doi:10.1016/j.egypro.2009.02.308

17. Winner L (1986) The whale and the reactor: a search for limits in an age of high technology. University of Chicago Press, Chicago

18. Wynne B (1988) Unruly technology: practical rules, impractical discourses and public understanding. Soc Stud Sci. doi:10.1177/ 030631288018001006

19. Jasanoff S (2004) States of knowledge: the co-production of science and social order. Routledge, London

20. Jasanoff S, Kim S-H (2009) Containing the atom: sociotechnical imaginaries and nuclear power in the United States and South Korea. Minerva. doi:10.1007/s11024-009-9124-4

21. Nilsson M, Nilsson LJ et al (2011) The missing link: bringing institutions and politics into energy future studies. Futures. doi:10. 1016/j.futures.2011.07.010

22. Frow E, Calvert J (2013) Opening up the future(s) of synthetic biology. Futures. doi:10.1016/j.futures.2013.03.001 
23. Yin RK (2008) Case study research: design and methods, 4th edn. Sage Publications, Thousand Oaks

24. ZEP (2006) A Vision for Zero Emission Fossil Fuel Power Plants. European Commission. ftp://ftp.cordis.europa.eu/pub/fp7/energy/ docs/zero emission ffpp en.pdf. Accessed 13 June 2013

25. ZEP (2006) Strategic Research Agenda. ZEP. http://www. zeroemissionsplatform.eu/extranet-library/publication/48-sra.html. Accessed 14 June 2013

26. ZEP (2006) Strategic Deployment Document. ZEP. http://www. zeroemissionsplatform.eu/extranet-library/publication/45-sdd.html. Accessed 14 June 2013

27. TNS Opinion \& Social (2011) Special Eurobarometer 364 Public Awareness and Acceptance of $\mathrm{CO} 2$ capture and storage. European Commission. http://ec.europa.eu/public_opinion/archives/ ebs/ebs_364_en.pdf. Accessed 13 June 2013

28. Schot J, Rip A (1996) The past and future of constructive technology assessment. Technol Forecast Soc Chang. doi:10. 1016/S0040-1625(96)00180-1

29. Sundqvist G, Elam M (2010) Public involvement designed to circumvent public concern? The "participatory turn" in European nuclear activities. Risk Hazards Crisis Public Policy. doi:10.2202/ 1944-4079.1046

30. ZEP (2010) Capturing and storing CO2: The hard facts behind CCS. ZEP. www.zeroemissionsplatform.eu/library/publication/ 102-the-hard-facts-behind-ccs.html. Accessed 14 June 2013

31. ZEP (2008) CO2 Capture and Storage (CCS): Why it is essential to combat global warming. ZEP. www.zeroemissionsplatform.eu/ library/publication/16-why-ccs-is-necessary.html. Accessed 14 June 2013

32. Wynne B (1992) Misunderstood misunderstanding: social identities and public uptake of science. Public Underst Sci. doi:10.1088/ 0963-6625/1/3/004

33. Guston DH (2001) Boundary organizations in environmental policy and science: an introduction. Sci Technol Hum Values. doi:10.1177/ 016224390102600401

34. Dryzek JS (1997) The politics of the earth: environmental discourses. Oxford University Press, Oxford

35. Callon M (1986) Some elements of a sociology of translation: domestication of the scallops and the fishermen of St Brieuc Bay. In:
Law J (ed) Power, action and belief: a new sociology of knowledge? Routledge, London, pp 196-223

36. Greenpeace (2008) False Hope. Greenpeace. www.greenpeace.org/ international/en/publications/reports/false-hope/. Accessed 15 June 2013

37. Corry O, Riesch H (2012) Beyond 'for or against': environmental NGO-evaluations of CCS as a climate change solution. In: Markusson N, Shackley S, Evar B (eds) The social dynamics of carbon capture and storage: understanding CCS representations, governance and innovation. Routledge, London, pp 91-108

38. Langhelle O, Meadowcroft J (2009) CCS in comparative perspective. In: Meadowcroft J, Langhelle O (eds) Caching the carbon: the politics and policy of carbon capture and storage. Edward Elgar Publishing, Cheltenham, pp 236-266

39. Radaelli CM (1999) The public policy of the European Union: whither politics of expertise? J Eur Public Policy. doi:10.1080/ 135017699343360

40. EC (2001) $\operatorname{COM(2001)~} 428$ final European governance: A white paper. European Commission. eur-lex.europa.eu/LexUriServ/site/ en/com/2001/com2001_0428en01.pdf. Accessed 14 June 2013

41. EC (2001) COM(2001) 714 final Communication from the Commission to the Council, the European Parliament, the Economic and Social Committee and the Committee of the Regions: Science and Society Action Plan. European Commission. eur-lex.europa.eu/ LexUriServ/LexUriServ.do?uri=COM:2001:0714:FIN:EN:PDF. Accessed 14 June 2013

42. EC (2002) Communication from the Commission on the Collection and Use of Expertise by the Commission: Principles and Guidelines "Improving the knowledge base for better policies". European Commission. ec.europa.eu/governance/docs/comm_expertise_en.pdf. Accessed 13 June 2013

43. Claes DH, Frisvold P (2009) CCS and the European Union: magic bullet or pure magic? In: Meadowcroft J, Langhelle O (eds) Caching the carbon: the politics and policy of carbon capture and storage. Edward Elgar Publishing, Cheltenham, pp 211-235

44. Mitchell T (2011) Carbon democracy: political power in the age of oil. Verso, London

45. Wilson EJ, Gibbons AJ (2007) Deploying carbon capture and storage in Europe and the United States: a comparative analysis. J Eur Environ Plan Law. doi:10.1163/187601007X00280 